\title{
AS DIFERENTES FACES DO AMBIENTE DE TRABALHO EM SAÚDE*
}

[The different faces of the health working environment]

Samantha Reikdal Oliniski**

Maria Ribeiro Lacerda***

RESUMO: Esta reflexão teórica tem por objetivo apresentar algumas das faces do ambiente de trabalho em saúde enquanto locus operandis do profissional da saúde. Assim, são tecidas considerações acerca da estrutura e organização do trabalho em saúde, das dificuldades enfrentadas pelo profissional de saúde e das oportunidades para este. Enfatizam-se em relação à estrutura e organização do trabalho em saúde as questões políticas e macro-institucionais do trabalho; considera-se nas dificuldades os diferentes fatores que afetam a saúde, o bem-estar e o equilíbrio psico-emocional do profissional de saúde; e são delineados nas oportunidades algumas características que permitem ao trabalhador satisfação, prazer e reconhecimento no trabalho. Deste modo, acredita-se que para ter uma visão mais abrangente e crítica em relação ao trabalho em saúde deve-se considerar o todo complexo que o compõe. Além disso, para que mudanças nas mais variadas nuances sejam efetivas é necessária a participação e contribuição de cada parte constituinte: instituições, profissionais e sociedade.

PALAVRAS-CHAVE: Trabalho; Ambiente de Trabalho; Condições de Trabalho; Ambiente de Instituições de Saúde.

\footnotetext{
*Trabalho apresentado à disciplina MN 716 - Enfermagem e sua Prática Profissional do Curso de Mestrado em Enfermagem, Programa de PósGraduação em Enfermagem - Universidade Federal do Paraná.

**Enfermeira. Mestranda em Enfermagem pela Universidade Federal do Paraná - UFPR. Bolsista da CAPES. Membro do Núcleo de Estudos,

Pesquisa e Extensão em Cuidado Humano de Enfermagem NEPECHE.

${ }^{* \star \star}$ Enfermeira. Doutora em Filosofia de Enfermagem. Professora Adjunta da UFPR. Vice-coordenadora do NEPECHE.
}

\section{INTRODUÇÃO}

O mundo do trabalho é bastante amplo e complexo e possui tantos desdobramentos que podem ser analisados sob diferentes prismas. Cada qual mostrará ao observador apenas uma face a ser contemplada, apenas uma fração do todo que o compõe. O trabalho em saúde é um dos recortes possíveis a ser considerado e este, assim como o trabalho em geral, apresenta diferentes faces, aspectos, formas de ser percebido e compreendido enquanto locus operandis do profissional da saúde.

Neste trabalho serão enfocadas três das múltiplas faces que esse ambiente possui: a estrutura e organização do trabalho em saúde, as oportunidades para o profissional de saúde e as dificuldades por este enfrentadas. Assim, essa reflexão teórica pretende apresentar algumas faces do ambiente de trabalho em saúde.

Entretanto, antes de apresentar tais faces, é necessário definir e contextualizar o que será considerado como ambiente de trabalho nesta reflexão. Retomam-se, assim, os conceitos de ambiente e trabalho, para então, formular o de ambiente de trabalho.

Ambiente, em seu sentido etimológico, refere-se ao que está ao redor, em torno. Para Radünz (1998, p. 17) ambiente "é o contexto interno e externo no qual o ser humano vive, interage, cresce e se desenvolve, desempenhando nele os seus papéis. Do contexto fazem parte os seres humanos, com suas respectivas crenças, valores, culturas, outros seres, objetos, etc., com os quais nos relacionamos e/ou interagimos".

O trabalho, por sua vez, desde sua origem é referido como sofrimento, esforço, obrigação. 
Lunardi Filho e Leopardi (1999, p. 21) afirmam que "entende-se por trabalho qualquer atividade que altera o estado das coisas para melhorar sua utilidade e para, dessa forma, melhor satisfazer as necessidades dos homens. Trabalho é, portanto, o esforço, enquanto processo e ação, e o resultado, enquanto obra concluída". Esses autores consideram ainda que o trabalho é algo muito mais amplo do que a aquisição de bens e manutenção da sobrevivência. Para eles o trabalho representa também a condição de realização, por meio da qual o homem se exterioriza e se dignifica.

Corroborando com essa concepção de trabalho além de produção material e busca pela sobrevivência, Ferreira (2003, p. 463-4) refere que o trabalho é sobretudo "um espaço de relação, de uma convivência social que realimenta em cada um o sentimento de inclusão e, simultaneamente, de sua diferenciação numa comunidade profissional e/ou institucional". Portanto, o trabalho possui um aspecto de grande relevância e um significado simbólico muito forte, ele é um espaço de socialização e dá sentido à vida das pessoas. No entanto, não pode ser considerado como único aspecto relevante da vida humana, mas, ao mesmo tempo, não deve ser marginalizado.

Tomando por base essas acepções, é possível delinear um conceito para ambiente de trabalho em saúde: contexto físico, psicológico, social e relacional dos profissionais de saúde, no qual cada um destes seres humanos possui um papel específico e interage constantemente com outros seres humanos, que podem ser pessoas da mesma categoria profissional, membros da equipe multiprofissional, clientes ou familiares destes. Caracteriza-se pela convivência em um espaço comum e pelo compartilhar de objetivos: recuperação, tratamento, manutenção e restauração da saúde e do indivíduo que precisa deste tipo de atenção.

É sob esta ótica que serão realizadas considerações acerca das diferentes faces do ambiente de trabalho enquanto locus operandis do profissional da saúde. Dessa forma, apresentase a seguir a estrutura e organização do trabalho em saúde, as dificuldades enfrentadas pelo profissional de saúde, bem como as oportunidades para o trabalhador de saúde.

\section{ESTRUTURA E ORGANIZAÇÃO DO TRABALHO EM SAÚDE}

A estrutura e organização do trabalho estão relacionadas à sua divisão técnica e social, ou seja, à hierarquia institucional, ao processo e ritmo de trabalho, à distribuição de atividades entre os profissionais, aos tipos e níveis de sociabilidade e comunicação estabelecidas na organização, aos níveis de formação e especialização do trabalho.

Dependendo da forma como a instituição está estruturada e organizada internamente os profissionais terão melhores ou piores condições de trabalho; possibilidade ou não de desempenho intelectual e manual; acesso a recursos e hierarquias institucionais; relacionamento e intercâmbio interpessoal; percepção sobre si, seu trabalho e a influência/importância do mesmo para a comunidade interna e externa; níveis de satisfação e desgaste, entre outros.

Muitas são as publicações que abordam estes aspectos, enfatizando principalmente os efeitos negativos que a estrutura e a organização do trabalho podem produzir nos trabalhadores. Estas questões serão tratadas com maior abrangência no próximo item.

Ao analisar a estrutura e a organização do trabalho, é necessário ainda abordar as influências externas à instituição que, não apenas a afetam, mas também os trabalhadores, a população e o país como um todo. Portanto, serão tecidas algumas breves considerações a respeito do capitalismo, globalização e mercado de trabalho, uma vez que constituem aspectos importantes em relação ao mundo do trabalho em saúde.

Jaques Wagner (2003, p. 452), ex-ministro do Trabalho e Emprego, afirma que no sistema capitalista, a inclusão social é ditada pelo mercado de trabalho, uma vez que este é o elo entre o crescimento econômico e o bem-estar material das famílias. Pondera que cabe às instituições e regulamentações trabalhistas a busca pelo melhor funcionamento e estrutura para que haja uma "alocação mais eficiente dos recursos produtivos e uma melhor distribuição da renda". Logo, possuir um emprego significa participar da sociedade e do círculo de desenvolvimento econômico e social.

Por outro lado, Wagner (2003) refere que o mercado de trabalho brasileiro nos últimos dez 
anos vem sofrendo uma desestruturação que tem trazido como conseqüências: a elevação do desemprego, o crescimento da informalização das relações trabalhistas, a estagnação da renda do trabalho e a piora na distribuição da renda. Colocações corroboradas por Ferreira (2003), que acrescenta a estas a terceirização e outros processos que considera socialmente cruéis como a flexibilização e o downsizing. Todo esse conjunto de ações tem conduzido a precarização do trabalho.

Outro aspecto relevante em relação à estrutura e organização do trabalho são os modelos atuais de gestão organizacional, que têm exigido dos profissionais não apenas qualificação e competências objetivas relativas à sua função, mas também exigências subjetivas. Ferreira (2003) considera tais exigências como invasão de privacidade, pois se inserem dentro de uma perspectiva de crescente dominação e colonização da subjetividade. Deste modo, alerta para que esta invasão da subjetividade e individualidade dos trabalhadores não ponha à prova sua identidade, e, conseqüentemente, leve a uma erosão de sua auto-estima e até mesmo dignidade.

Este autor aponta ainda a existência de dois fenômenos paralelos, nos quais de um lado está o número crescente de pessoas excluídas do trabalho formal, e no reverso estão os empregados, que por um lado são considerados privilegiados e protegidos por ainda possuírem direitos e benefícios. Os primeiros acabam ficando à margem da precariedade e informalidade. O segundo grupo são os que, apesar de tudo, reclamam e percebem o volume crescente de deveres e obrigações impostas, fazendo com que atinjam um nível de performance profissional praticamente impossível.

Assim, a lógica capitalista privilegia a produção e o lema é produzir e produzir cada vez mais, para poder então desfrutar de alguns benefícios. Segundo Ghiorzi (2003, p. 553), muitos trabalhadores de saúde se enquadram nessa lógica e consideram que "devem trabalhar até a fadiga, consagrando a maior parte do seu tempo ao trabalho, num processo de competição e solidariedade, de resistência e de atração para encontrar-se com o outro (cliente, familiar, colega)". Deste modo, percebe-se que o trabalho fica pautado apenas nos princípios da produtividade, eficiência, competitividade e racionalidade.

De acordo com Lunardi Filho e Leopardi (1999, p. 43) o resultado de toda essa situação tem sido a "desqualificação e marginalização contínuas, traduzidas por situações de nãoaproveitamento ou má-utilização das potencialidades e da criatividade do trabalhador. Além de não dignificar e não favorecer a emergência de sentimentos de realização e de prazer no trabalho, tem conduzido à degradação das condições de vida de uma parcela cada vez maior e significativa da população ativa".

Percebe-se que a adoção desse modelo trabalhista tem levado à exploração, alienação e desumanização do trabalhador, bem como à marginalização daqueles que não possuem vínculo empregatício formal. No entanto, não se pode tomar esse modelo como único vilão e culpado por todas as mazelas, é necessário que os trabalhadores em saúde tenham consciência desses aspectos subjacentes ao trabalho e, a partir disso, comecem a agir e buscar alternativas para modificar a situação vigente a seu favor.

\section{DIFICULDADES ENFRENTADAS PELO PROFISSIONAL DE SAÚDE}

Diante do panorama do trabalho apresentado anteriormente, muitos são os fatores ou elementos que podem ser elencados como dificuldades enfrentadas pelo trabalhador de saúde. Neste trabalho serão apresentados alguns desses aspectos sem, no entanto, esgotar o assunto.

Lunardi Filho e Leopardi (1999) levantaram como fontes de insatisfação profissional dos trabalhadores de saúde os seguintes aspectos: o descompasso da assistência à saúde enquanto resultado da deformação do sistema de saúde; a incoerência entre as necessidades e as finalidades do trabalho em saúde; a existência de uma fragilidade teórica por um lado, e de uma cristalização da prática, por outro; a adesão ainda presente ao modelo biomédico de saúde; e a ausência de políticas de saúde claras e consistentes com a mentalidade social em construção.

Percebe-se que tais elementos estão diretamente relacionados às questões abordadas anteriormente. Referem-se aos fatores mais amplos e políticos que envolvem o trabalho em saúde, portanto, dependem muito dos aspectos 
subjacentes ao trabalho, mas ao mesmo tempo refletem uma postura gessada por parte dos profissionais ao apenas reproduzir e, conseqüentemente, manter o modelo de saúde vigente.

Sob outra ótica, Ghiorzi (2003, p. 554) aponta para um esvaziamento das relações e ações dos trabalhadores de saúde. Afirma que "não há mais paixão naquilo que fazem, porque o tempo para o prazer de escutar um cliente, de dar atenção a ele é substituído pelo tempo de aumentar as horas de trabalho e do número de pessoas atendidas", o que acaba conduzindo ao esgotamento físico e psíquico.

Frente a essa situação, Lunardi Filho e Leopardi (1999, p. 35) referem que se tem como consequência do esvaziamento afetivo, "a insatisfação, o absenteísmo, o desejo de abandonar e, até mesmo, o abandono da profissão. Há o prejuízo da qualidade do trabalho, decorrentes da perda do interesse por ativudades que são esvaziadas de significado e que não costumam resultar em reconhecimento, nem dos pacientes, nem da hierarquia hospitalar".

Deste modo, o trabalho em saúde acabou por perder seu significado de ajuda, recuperação, restauração da saúde, para tornar-se apenas uma prestação de serviço mecânica e massificada, esvaziada de conteúdo e valores humanos. Uma explicação possível para isso são as características peculiares do ambiente de trabalho em saúde e o tipo de relacionamento estabelecido neste contexto.

Lopes e Laufert (2001) referem que este ambiente é caracterizado por um trabalho que envolve uma forte carga emocional, na qual vida e morte se misturam, compondo assim um cenário desgastante e, muitas vezes, frustrante. Outros fatores presentes são "o lidar com o sofrimento do paciente e da família, o fazer específico da profissão (que requer agilidade, atenção, renovação de conhecimentos técnicos), a necessidade de improvisação, as questões de ordem burocrática, o inter-relacionamento com a equipe e o barulho constante dos aparelhos" (COUTRIN, FREUA e GUIMARÃES, 2003, p. 492).

Deste modo, os trabalhadores reagem ou buscam alternativas de enfrentamento variadas, utilizando os recursos de que dispõem. Entretanto, nem sempre os recursos utilizados são adequados às situações. Como aponta Ghiorzi (2003, p. 553) "a solidão dos trabalhadores de saúde, o excesso de trabalho e de responsabilidades, a falta de férias, de horas de repouso, de prazer e de criação, de espaço para a discussão sobre a sua vida e seus limites, são responsáveis pela explosão de carga psicológica, muito pesada dos trabalhadores em saúde". Segundo o autor, essa forte carga psicológica, e por quê não dizer também emocional, pode levar o profissional a cometer erros e a adotar atitudes extremas como a prática da eutanásia frente à dor e ao sofrimento do cliente.

Quanto à forma de relacionamento desenvolvida no ambiente de trabalho, nota-se que muitas vezes as relações interpessoais são destrutivas, não favorecendo a auto-estima e a paz mental. As pessoas têm dificuldade para estabelecer e manter relacionamentos construtivos, solidários, éticos e pautados na construção conjunta e no respeito pelas capacidades e limites do outro, seja do colega de trabalho, seja do cliente ou familiares.

Diante de todas essas questões, Ghiorzi (2003, p. 555) afirma:

\footnotetext{
"Os lugares de conversação informais para um café, uma pausa na jornada de trabalho, os corredores, as salas dos plantonistas se transformam em lugares de sonhos, de fuga às regras, de queixas, de lamentos, de choros, de risos à toa, de piadas, de medo, de prazer, em resumo, lugares onde podem aflorar as suas emoções frente à precariedade da vida e de seus sabores. É o momento em que eles lutam contra a invasão do sentimento de fracasso e de frustração frente às medidas que podem tomar para aliviar o sofrimento do cliente."
}

Grande parte dos aspectos apontados até aqui se configura como fontes ou fatores desencadeantes de estresse no profissional de saúde, outro tema freqüentemente alvo de considerações na literatura, principalmente nos últimos cinco anos.

Dentre os principais fatores geradores de estresse no ambiente de trabalho, Costa e Lima (2003) apontam a organização, administração e o sistema de trabalho, e as relações humanas existentes nesse contexto.

De acordo com Andrews (2001) três são os aspectos relacionados ao estresse: o evento 
estressante, a avaliação interna do indivíduo e a reação fisiológica. Destaca que a percepção que a pessoa possui acerca do estresse é o aspecto mais significativo, pois dela dependerá sua resposta fisiológica, bem como a atitude a ser adotada frente à situação. Assim, o estresse pode, também, ser positivo na medida em que sirva de estímulo para o desenvolvimento de determinada atividade. "Quando o estresse é percebido positivamente como um desafio, pode despertar o que há de melhor numa pessoa; quando é experenciado como negativo, pode levar ao adoecimento" (ANDREWS, 2001, p. 58).

Outro aspecto que tem sido alvo de discussões e reflexões no âmbito do trabalho é o assédio moral. Este é um tema que merece destaque, pois é um aspecto bastante grave e preocupante que pode desestruturar completamente a vida de uma pessoa, não apenas no que concerne ao trabalho, mas a sua autoestima e valorização pessoal; é, no entanto, muitas vezes negligenciado ou velado.

Hirigoyen (2002, p. 17) define assédio moral como "qualquer conduta abusiva (gesto, palavra, comportamento, atitude...) que atende, por sua repetição ou sistematização, contra a dignidade ou integridade psíquica ou física de uma pessoa, ameaçando seu emprego ou degradando o clima de trabalho".

O assédio moral caracteriza-se pela persistência, uma vez que uma ação considerada isoladamente não é configurada como grave. É a insistência e o efeito cumulativo que determinam a agressão. O termo moral é utilizado para designar a importância da humilhação e a falta de respeito envolvidas.

A forma pela qual a agressão se dá é variável, depende do meio sociocultural e dos setores profissionais em questão. "Nos setores de produção, a violência é mais direta. Verbal ou física. Quanto mais se sobe na hierarquia e na escala sociocultural, mais as agressões são sofisticadas, perversas e difíceis de caracterizar" (HIRIGOYEN, 2002, p. 18).

Para que fique claro o que é o assédio moral, pode-se diferenciá-lo de outras fontes de desgaste e injúria nos trabalhadores, por isso, a princípio não é assédio moral: estresse, conflitos, gestão por injúria, agressões pontuais, más condições de trabalho, imposições profissionais. Mesmo que tais condições conduzam a efeitos semelhantes aos do assédio, não produzem sentimentos tão destrutivos, não possuem alvos específicos, ou seja, não há, na maioria das vezes, uma única pessoa a ser vitimizada, não há intenção de prejudicar o trabalhador e, além disso, os efeitos apresentados pelos trabalhadores tendem a desaparecer à medida que se eliminam os agentes causadores, diferentemente do que ocorre no assédio moral, no qual, mesmo distante do estímulo os sintomas persistem. No entanto, dependendo da intensidade, freqüência, intencionalidade e persistência da situação, esta pode, sim, ser caracterizada como assédio moral.

Os sentimentos mais comuns produzidos pelo assédio moral são os seguintes: maltrato, desprezo, humilhação e rejeição. "As sintomatologias apresentadas pelas vítimas são muito caricatas e estão mais relacionadas à intensidade e duração da agressão do que propriamente às estruturas psíquicas" (HIRIGOYEN, 2002, p. 157).

No início, os sintomas se assemelham aos do estresse (cansaço, nervosismo, enxaquecas, distúrbios do sono, etc.), somados à sensação de impotência, humilhação e de que a situação não é normal. Se a pessoa neste momento for afastada do agente causador poderá se recuperar e reequilibrar sem maiores conseqüências. "Mas, se o assédio moral se prolonga por mais tempo ou recrudesce, um estado depressivo mais forte pode se solidificar. A pessoa assediada apresenta então apatia, tristeza, complexo de culpa, obsessão e até desinteresse por seus próprios valores" (HIRIGOYEN, 2002, p. 159-60). Desta forma, o assédio moral faz com que a pessoa se sinta ferida, desgastada, inútil, derrotada, sem auto-estima, ilusão ou esperança.

Utilizando o estudo do Belancieri e Bianco (2004) sobre os fatores desencadeadores de estresse e suas repercussões psicossomáticas nos trabalhadores de enfermagem, pode-se fazer uma síntese das principais dificuldades enfrentadas pelo profissional de saúde no ambiente de trabalho.

Os referidos fatores e dificuldades encontram-se nos seguintes grupos: 1) fatores burocráticos, relacionados ao excessivo controle institucional sobre o trabalho, conflitos entre 0 trabalho e responsabilidades pessoais e familiares, e freqüentes interrupções nas atividades; 2 ) 
relacionamento interprofissional, relativo à relação de poder e dominação no ambiente de trabalho, o descompromisso ético dos profissionais, à percepção de desempenho profissional insatisfatório de colegas, à falta de lealdade e cooperação entre os colegas e dificuldades de relacionamento profissional; 3) desempenho profissional, no qual foram apontadas as atividades repetitivas e rotineiras, o excesso de clientes atendidos, a tensão e ansiedade ao lidar com o sofrimento e morte, a precariedade da infraestrutura institucional, a indefinição de responsabilidades, a tensão ao prestar serviços ao cliente e a percepção do ambiente de trabalho como algo desagradável; 4) reconhecimento social e econômico, referente à remuneração insuficiente, à falta de condições de lazer, a não valorização e reconhecimento institucional do trabalho e méritos profissionais do trabalhador, à desconsideração dos superiores quanto às sugestões e recomendações, e a dificuldade para conseguir apoio e/ou recursos para aprimoramento profissional (BELANCIERI E BIANCO, 2004, p. 128).

Muitos seriam os aspectos que poderiam ser elencados neste momento, pois é fácil destacar, perceber o que não agrada, o que fere. É natural do ser humano a insatisfação e a crítica às coisas que estão ao seu redor, no entanto, é necessário observar as duas faces da moeda: a ruim e a boa, pois ao mesmo tempo que existem dificuldades há também as oportunidades decorrentes, que muitas vezes se esquece de valorizar.

\section{OPORTUNIDADES PARA O PROFISSIONAL DE SAÚDE}

Se por um lado é fácil levantar as dificuldades referentes ao trabalho em saúde, por outro encontrar estudos que apontem as suas oportunidades não é tarefa tão simples. Poucos foram os achados a respeito, e a maioria destes contemplava os dois pólos.

$\mathrm{O}$ aspecto mais comumente encontrado foi o concernente ao trabalho em saúde em si, ou seja, o fato de com ele ser possível proporcionar conforto e alívio aos clientes, ajudar o outro, fazer diferença, ter impacto na vida/saúde das pessoas (PEREIRA e FÁVERO, 2001; MARTINS, 1999). Assim, ser profissional da saúde significa muitas vezes ser uma pessoa que tem importância, que exerce uma atividade que tem reconhecimento e valorização social.

Este aspecto é importante, pois reflete diretamente na percepção de si do profissional, no sentimento de utilidade, na sua auto-estima, e serve como impulsor e motivador de seu trabalho. Ter impacto na vida das pessoas e ser capaz de influenciá-las no processo de saúde-doença, na prevenção ou promoção da saúde, fazer parte de um momento tão significativo são realmente fatores fundamentais e inerentes ao trabalho em saúde.

Fazer parte de uma equipe de saúde é outra oportunidade encontrada nesse ambiente de trabalho. Significa fazer parte do processo coletivo, estar engajado e comprometido com sua atividade e trabalhar em conjunto com demais profissionais, o que facilita o intercâmbio de idéias, promove discussão e reflexão, e possibilita o aprendizado contínuo e crescimento em conjunto.

Para Ciampone e Peduzzi (2000, p.144) o trabalho em equipe envolve duas dimensões: a articulação das ações e interação dos profissionais. A articulação refere-se à "recomposição de processos de trabalho distintos e, portanto, a consideração das conexões e interfaces existentes entre as intervenções técnicas peculiares de cada área profissional, bem como a preservação das respectivas especificidades". Já a integração da equipe "demanda, simultaneamente, preservar as diferenças técnicas e flexibilizar as fronteiras entre as áreas profissionais". Deste modo, de acordo com as autoras, o trabalho em equipe ocorre quando os profissionais conseguem se comunicar e consideram a prática dos demais como interdependente e complementar a sua, e assim negociam e trabalham tendo em vista os mesmos objetivos.

Diante deste contexto a autonomia profissional também pode ser considerada como um elemento positivo para o profissional de saúde, pois por meio dela este pode tomar suas próprias decisões, agir e se posicionar frente às situações, adotar condutas, comprometer-se e ter noção de seus limites profissionais.

Assim, coadunando com Leddy e Pepper (1993), autonomia significa que as pessoas têm controle sobre suas funções próprias no cenário 
do trabalho, envolve independência, disposição para assumir riscos, e responsabilidade sobre suas próprias ações, bem como autodeterminação e auto-regulação. Desta forma, enquanto profissional autônomo, o trabalhador de saúde possui conhecimentos para agir, conhece sua esfera de atuação, assume as conseqüências de suas ações e respeita o outro.

Além disso, o trabalho em saúde propicia ainda o desenvolvimento de atividades diferentes e complementares como a assistência, o ensino e a pesquisa. Tais atividades expandem o leque de possibilidades de atuação, favorecem a utilização de diferentes processos mentais e manuais, auxiliam no desenvolvimento de habilidades, permitem uma visão ampliada e articulada de mundo e trabalho, estimulam o desenvolvimento da criatividade, e a expressão e o fluxo de idéias.

Ferreira (2003) comenta que no ambiente de trabalho existem dois processos essenciais que envolvem o profissional e determinam sua satisfação no trabalho: o desejo de reconhecimento e o reconhecimento do desejo. $\mathrm{O}$ primeiro refere-se ao desejo que todo ser humano possui de ser reconhecido e o faz buscar a inclusão dentro de um grupo, ser visto como igual e membro deste (identidade coletiva). No segundo, além desse reconhecimento, a pessoa busca a expressão de suas peculiaridades, das diferenças, daquilo que os faz únicos (identidade individual). Assim, a medida em que há possibilidade ou expressão dessas necessidades os profissionais experimentarão satisfação ou sofrimento no trabalho.

Em relação ao segundo aspecto pode-se apontar o uso da criatividade no desenvolvimento do trabalho, tendo em vista que a capacidade de criar/transformar é uma dos fatores responsáveis pelo prazer pelo trabalho. Azambuja, Kerber e Vaz (2003, p. 291) afirmam a esse respeito que a criatividade "possibilita ao ser humano a participação ativa no processo de transformar a realidade, assegurando-Ihe que sua singularidade pode se manifestar, no coletivo do qual faz parte, através de suas ações, de suas reflexões". Assim, segundo os autores, ao tornar-se um membro ativo do processo de trabalho e não apenas um executor de tarefas pré-determinadas, o trabalhador poderá acrescentar tanto qualidade como prazer ao seu trabalho.

Ainda considerando essas necessidades de reconhecimento do profissional no ambiente de trabalho, alguns autores propõe a criação ou uso de algumas estratégias que promovam uma mudança organizacional e permitam a expressão da subjetividade e individualidade dos trabalhadores, possibilitando-Ihes assim um aumento na satisfação, a realização de um trabalho significativo e no qual os valores humanos estejam presentes.

Neves (2002) transpõe a visão de Watson para o contexto de trabalho e propõe a criação de um ambiente de cuidado que tenha alma, ou seja, um ambiente no qual os valores morais e a atitude ética favoreçam a preservação da dignidade, respeito e solidariedade entre os profissionais. De acordo com a autora "é preciso criar um ambiente favorável que seja afetuoso, caloroso, atencioso, amoroso e que propicie crescimento, alívio, segurança, proteção, bem-estar, ou seja, um ambiente no qual a pessoa experiencie o cuidado humano", evitando que "a inércia, o desespero, o desamparo e o sofrimento sejam os companheiros de caminhada no mundo do trabalho" (NEVES, 2002, p. 135-136).

A autora também incita o profissional de saúde a encontrar formas de cuidado para promover a vida, para estimular o poder vital e a saúde para transformar o trabalho em prazer, acalmando e aliviando os trabalhadores nos constantes tormentos que enfrentam no cotidiano. Enfim, para promover conforto no processo de viver, incentivando-os a alcançarem o bem-estar e a melhor qualidade de vida possível (NEVES, 2002, p. 136).

Já Ferreira (2003, p.464) propõe a vazão ao imaginário e as representações sociais dos indivíduos, permitindo a reapropriação de significados e a "expressão das dimensões pessoais e subjetivas, individuais e coletivas, mais coerentes com as respostas de que necessitam para nutrir sua identidade". Sugere assim criação de um plano administrativo que considere as diferentes necessidades dos trabalhadores e dos clientes, proporcionando uma comunicação permanente e favorecendo a atualização e renovação da política institucional.

Hirigoyen (2002, p. 27) afirma a necessidade dos profissionais se unirem e adotarem posturas 
diferenciadas no ambiente de trabalho, pois considera que "cada um sofre no seu canto sem compartilhar suas dificuldades com um grupo solidário". Acrescenta ainda que "os trabalhadores não têm mais o sentimento de pertencer a um coletivo profissional que poderia lhes permitir a busca conjunta do reconhecimento".

Dentro desta perspectiva Lunardi Filho e Leopardi (1999, p. 19) contemplam o viver a possibilidade da solidariedade no ambiente de trabalho, o que se constitui no "desafio de oferecer e receber ajuda, como valor a ser cultivado, como afirmação da superioridade nas relações, uma vez que ao olhar outro ser humano, estamos diante de nossa própria fragilidade pela identificação com o outro".

Desta forma, corroborando com Ferreira (2003, p.468), ao se perceber e valorizar a subjetividade dos indivíduos, é possível ir além das motivações racionais e objetivas que conduzem ao trabalho, ou seja, pode-se compreender seus valores e sentimentos, os quais conferem um "senso de unidade e de identidade, em suas dimensões verdadeiramente humanas, através das quais elas não só cooperam, ou seja, trabalham juntas, mas também convivem e se relacionam, criando e valorizando vínculos, com o trabalho, com o mundo, com os outros e, sobretudo, consigo mesmas, construindo-se e se reafirmando como sujeitos efetivos em sua ação".

Neste sentido, "sendo agente de transformação do cotidiano de trabalho, envolvendo-se com práticas seguras, preocupando-se e produzindo condições adequadas às necessidades dos pacientes/ clientes e de si mesmo, o ser humano estará transformando, igualmente, a sociedade na qual está inserido" (AZAMBUJA, KERBER e VAZ, 2003, p. 292).

\section{CONSIDERAÇÕES FINAIS}

Por meio das reflexões realizadas neste estudo, percebe-se que o trabalho exerce um papel fundamental na vida do ser humano. Deste modo, o ambiente de trabalho não pode ser visto sob uma única ótica, é necessário que sejam consideradas as suas diferentes faces.

Apresentaram-se aqui algumas delas: a estrutura e organização do trabalho em uma perspectiva mais ampla, considerando as políticas e aspectos macro-institucionais que interferem e participam do contexto do trabalho em saúde; as dificuldades enfrentadas pelo profissional de saúde e as oportunidades referentes ao trabalho em saúde. Ao considerar estas três faces, buscou-se mostrar aspectos diferentes e complementares que permeiam o ambiente de trabalho em saúde, visando uma compreensão mais abrangente e contextualizada desse conjunto. Aponta-se ainda para a inter-relação existente entre essas faces.

Para que haja uma efetiva mudança nos ambientes de trabalho, é necessário que se tenha conhecimento e se compreendam os fatores que neles interferem e que estão além dos limites institucionais, como é o caso do universo político e do mundo capitalista no qual se está inserido. Além disso, é importante, também, que sejam consideradas as formas atuais de estruturas e organização destes ambientes, adotando uma visão crítica e reflexiva frente às dificuldades apresentadas e buscando com os colegas e instituição uma readequação e ordenação mais favorável à saúde do trabalhador. Igualmente, que os profissionais e a instituição tenham consciência das oportunidades relacionadas ao ambiente de trabalho em saúde e deles façam o melhor uso possível, para dessa forma contemplar o maior número de aspectos envolvidos e assim desenvolver e implementar ações mais assertivas e factíveis, que beneficiem todos os envolvidos no processo: profissionais de saúde, instituição e sociedade, a qual terá como conseqüência um atendimento diferenciado aos clientes e familiares.

Portanto, para que qualquer intervenção ou modificação tenha êxito no ambiente de trabalho, cada um deve contribuir com sua parte, ou seja, não basta apenas instrumentalizar os profissionais, ensinando ou desenvolvendo técnicas de enfrentamento, se a estrutura permanece rígida, baseada em quantidade e produção. $E$ também não adianta adequar o espaço físico do ambiente se não existe espaço relacional concreto propício para trocas e compartilhamento. Cada qual precisa responder por sua parte: a instituição pelas políticas organizacionais, estruturas e ambientes condizentes; e os trabalhadores com a percepção da realidade, com idéias de mudança, 
readequação, denunciando o que não está correto e buscando alternativas viáveis para melhoria do seu ambiente de trabalho, além de adotar atitudes pessoais que retomem valores humanos como respeito, solidariedade, amor ao próximo e comprometimento.

Estas são apenas algumas faces a serem consideradas no vasto mundo do trabalho em saúde. Quanto mais faces forem contempladas no momento de observar e perceber esse contexto, em meio a tanta diversidade, maior será a visualização e compreensão do todo que o compõe.

ABSTRACT: This theoretical reflection aims to show some faces of the health working environment while locus operandis of the health professional. Therefore, considerations are made about the structure and organization of health work, difficulties faced by the health professional and opportunities for him/her. Regarding the structure and organization of health work are emphasized the political and macro-institutional matters of work; about the difficulties are considered the different factors that affect the health, well-being and psycho and emotional balance of health professional, and about the opportunities are outlined some characteristics that allow satisfaction, pleasure and valuing of the professional in the working environment. This way, we believe that to have a wider and critical view about the health work is necessary to consider the whole that composes it. Moreover, it is necessary the participation and contribution of every component: institutions, professional and society, in order to happen changes on these diverse nuances.

KEY WORDS: Work, Working Environment; Working Conditions, Health Facility Environment.

\section{REFERÊNCIAS}

ANDREWS, S. Stress a seu favor: como gerenciar sua vida em tempos de crise. São Paulo: Instituto Visão Futuro, 2001.

AZAMBUJA, E. P.; KERBER, N. P. C.; VAZ, M. R. C. A compreensão da organização do trabalho em saúde através da vivência dos trabalhadores com acidente de trabalho. Texto Contexto Enferm., Florianópolis, v. 12, n. 3, p. 289-297, jul./set. 2003.

BELANCIERI, M. F.; BIANCO, M. H. B. C. Estresse e repercussões psicossomáticas em trabalhadores da área da enfermagem de um hospital universitário. Texto Contexto Enferm. Florianópolis, v. 13, n. 1, p. 124-131, jan./mar. 2004

CIAMPONE, M. H. T.; PEDUZZI, M. Trabalho em equipe e trabalho em grupo no Programa de Saúde da Família. R. Bras. Enferm., Brasília, v. 53, n. especial, p.143-147, dez. 2000.

COSTA, J. R. A.; LIMA, J. V. Estratégias para o enfermeiro enfrentar o stress em seu trabalho com o portador de transtorno mental. Rev. Gaúcha Enferm. Porto Alegre, v. 24, n. 3, p. 325-335, dez. 2003.

COUTRIN, R. M. G. S.; FREUA, P. R.; GUIMARÃES, C. M. Estresse em enfermagem: uma análise do conhecimento produzido na literatura brasileira no período de 1982 a 2001. Texto Contexto Enferm., Florianópolis, v. 12, n. 4, p. 486-494, out./dez. 2003.

FERREIRA, L. C. Organização e relações de trabalho. Texto Contexto Enferm. Florianópolis, v. 12, n. 4, p. 461-469, out./dez. 2003.

GHIORZI, A. R. O quotidiano dos trabalhadores em saúde. Texto Contexto Enferm. Florianópolis, v. 12, n. 4, p. 551-558, out./dez. 2003.

HIRIGOYEN, M. F. Mal-estar no trabalho: redefinindo o assédio moral. Rio de Janeiro: Bertrand Brasil, 2002.

LEDDY, S.; PEPPER, J. M. Conceptual bases of professional nursing. Philadelphia: J. B. Lippicontt Company, 1993.

LOPES, M. J. M.; LAUTERT, L. A saúde das trabalhadoras da saúde: algumas questões. In: HAAG, G. S.; LOPES, M. J. M.; SCHUCK, J. S. (org.). A enfermagem e a saúde dos trabalhadores. Goiânia: AB, 2001. p. 109-40.

LUNARDI FILHO, W. D.; LEOPARDI, M. T. 0 trabalho da enfermagem: sua inserção na estrutura do trabalho geral. Rio Grande do Sul: FURG, 1999.

MARTINS, J. J. Qualidade de vida e trabalho: o cenário atual do trabalho da enfermagem numa unidade de terapia intensiva (UTI). Texto Contexto 
Enferm., Florianópolis, v. 8, n. 3, p. 128-146, set./ dez. 1999.

NEVES, E. P. Cuidando e confortando: uma estratégia para a saúde do trabalhador. Rev. Enferm. UERJ, Rio de Janeiro, v. 10, n. 2, p. 133137, maio/ago. 2002.

PEREIRA, M. C. A.; FÁVERO, N. A motivação no trabalho da equipe de enfermagem. Rev. Latinoam. Enfermagem, São Paulo, v. 9, n. 4, p. 7-12, jul. 2001.

RADÜNZ, V. Cuidando e se cuidando: fortalecendo o self do cliente oncológico e o self da enfermeira. Goiânia: AB, 1998.

SILVA, R. F.; ERDMANN, A. L. Ambiente de cuidado: dimensão ecológica. Texto Contexto Enferm. Florianópolis, v. 11, n. 3, p. 72-82, set./ dez. 2002.

WAGNER J. Os cenários do trabalho no Brasil. Texto Contexto Enferm. Florianópolis, v. 12, n. 4, p. 451-460, out./dez. 2003. 